\title{
RAP DA LINHA ABISSAL
}

Resumo em forma de rap da Aula Magistral do Professor Boaventura de Sousa Santos proferida a 15 de maio de 2017, em Coimbra, Portugal

\section{Renan Inquérito}

\section{(2) OpenEdition}

\section{Journals}

Edição electrónica

URL: http://journals.openedition.org/rccs/6850

DOI: $10.4000 /$ rccs. 6850

ISSN: $2182-7435$

Editora

Centro de Estudos Sociais da Universidade de Coimbra

\section{Edição impressa}

Data de publição: 1 dezembro 2017

Paginação: 243-244

ISSN: 0254-1106

\section{Refêrencia eletrónica}

Renan Inquérito, «RAP DA LINHA ABISSAL », Revista Crítica de Ciências Sociais [Online], 114 | 2017, posto online no dia 20 dezembro 2017, consultado o 23 setembro 2020. URL : http:// journals.openedition.org/rccs/6850 ; DOI : https://doi.org/10.4000/rccs.6850

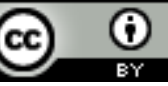




\section{Espaço Virtual}

Canal do Projeto Alice no Youtube: https://www.youtube.com/user/CESalice

URL da aula magistral "A Sociologia Pós-Abissal: Metodologias Não

Extractivistas" do Professor Boaventura de Sousa Santos, 15.05.2017: https://youtu.be/1SHnc6P7Z6A

Resumo em forma de rap da Aula Magistral do Professor Boaventura de Sousa Santos proferida a 15 de maio de 2017, em Coimbra, Portugal

\author{
RAP DA LINHA ABISSAL \\ SÃO TANTAS LINHAS QUE A \\ GENTE INVENTÔ \\ TEM LINHA DE MONTAGEM, \\ ATÉ LINHA RETRÔ \\ LINHA DE PENSAMENTO, LINHA \\ DO EQUADOR \\ LINHA DE TELEFONE, E LINHA \\ DE TRICÔ
}

LINHAS REAIS OU IMAGINÁRIAS LINHAS INÚTEIS E TÃO

NECESSÁRIAS

SÓ SIGO AQUILO QUE O POETA FALÔ

QUEM ANDA NA LINHA É TREM OU METRÔ

SOU ÁGUA QUE CORRE ENTRE AS PEDRAS (CAÇA JEITO)

LIBERDADE NINGUÉM CARREGA (EXPLODE O PEITO)

TÔ NA LINHA DE TIRO E NÃO

POSSO MOSCAR

NA LINHA POR UM FIO (PÁ!) NÃO POSSO VACILAR

ENTÃO SIGAMOS A UTOPIA A LA GALEANO
CONTINUO ANDANDO, VIVENDO

E SONHANDO

A ESPERANÇA ME MOVE ELA

É MINHA FONTE

SÓ SIGO UMA LINHA: A LINHA

DO HORIZONTE

VIVEMOS SEPARADOS NO MESMO QUINTAL

UMA LINHA ABISSAL

E A DIVISÃO ELA É TÃO

DESIGUAL

UMA LINHA ABISSAL

NÃO QUERO ACHAR NORMAL

ESSA LINHA ABISSAL

A LINHA QUE SEPARA O DISPARO CERTEIRO DO ACIDENTAL

LINHA ABISSAL

QUE FAZ O NAVIO NEGREIRO SER TÃO ATUAL

LINHA ABISSAL

QUE É UM ABISMO FÍSICO E

SOCIAL

LINHA ABISSAL

QUE PÕE DIREITOS HUMANOS

PRA SECAR NO VARAL

LINHA ABISSAL

QUE CRIA UM MUNDO

METROPOLITANO E OUTRO

COLONIAL 
LINHA ABISSAL

QUE TRANSFORMA A MISÉRIA

EM ALGO CULTURAL

LINHA ABISSAL

QUE É METAFÓRICA E LITERAL

LINHA ABISSAL

LINHAS

costuram tecidos, às vezes humanos

separam países, dividem contratos

\section{LINHAS}

do tempo no rosto, nas mãos do destino mantém pipas no céu pelas mãos

de meninos

\section{LINHAS na horizontal}

pautam cadernos, são trilhos prás letras

LINHAS na vertical

são barras, códigos que prendem

Ela já foi uma ligação lembra? Umbigo hoje é só uma cicatriz, uma marca, de egoísmo

Linha na agulha da máquina o vietnamita costura uma blusa USA, toda sua força (de trabalho) mas não consegue entender, porquê? aquela etiqueta vale $10 \mathrm{x}$ mais (valia) que seu salário

e o logotipo é de uma marca com sede no mesmo país

que matou seus avós com bombas, napalm e agente laranja

a linha da vida é tênue

Algum deus escreveu certo por linhas tortas

no desenho de um eletrocardiograma

e até mesmo a medicina, tão cética

e tão exata

aprendeu que a vida mora, nessas linhas sinuosas

e quando ela endireita nem sempre

é um bom sinal

VIVEMOS SEPARADOS NO MESMO QUINTAL

UMA LINHA ABISSAL

E A DIVISÃO ELA É TÃO DESIGUAL UMA LINHA ABISSAL

NÃO QUERO ACHAR NORMAL

ESSA LINHA ABISSAL

Renan Inquérito 


\title{
Canal do Projeto Alice no Youtube: https://www.youtube.com/user/CESalice/
}

\section{URL da aula magistral "É possível ser utópico hoje? \\ A utopia do futuro ou o futuro da utopia" do Professor Boaventura de Sousa Santos, 22.04.2016: https://youtu.be/OViEBnkJQAc}

\section{URL da leitura do poema: https://youtu.be/IUWHazexPgY}

\author{
Resumo poético da Aula Magistral do Professor Boaventura de Sousa \\ Santos proferida a 22 de abril de 2016, em Coimbra, Portugal
}

\section{Disparem sobre a utopista!}

Paira um fantasma no ar,

o de que todas as conquistas são frágeis

e reversíveis.

Tudo pode ser destruído de um dia para o outro,

Tudo o que é sólido se desfaz no ar...

E hoje?

Hoje quando observo e absorvo esta urgência,

esta necessidade de pensar para além do possível, do credível e do verosímil, quando percebo que a política degrada exponencialmente à medida que degrada a natureza,

quando percebo com toda a certeza que hoje, há esta urgência e esta necessidade no ar

De deixar de ver as notícias sobre injustiças do nosso tempo com essa naturalidade típica e conformista, duma indiferença atroz e nada salutar...

Esta necessidade de não querer ser só literária mas ser social

Esta necessidade impossível, e que por ser impossível é necessária

E não o contrário reformista que nos foram vendendo, vendando os olhos da cega

Porque muitos olham mas poucos vêem Que as expectativas de ver de uma cega são à partida negativas,
E que existe esse mal-estar, essa fragilidade de que tudo desapareceu aos seus olhos de um momento para o outro E que o seu olhar não se vai aperfeiçoando, nem mesmo depois de morta

A sua cegueira é já perfeita, completa, e por isso a sua visão só tem que ser nula Os seus olhos, são um território em que já não é possível a perfeição

E por isso já não é preciso sonhar, quando já se tornou irreversível a sua exclusão de todos os lugares, a da cega Aqui na nossa cegueira o fim chegou antecipado, apocalíptico, desastroso, e aqui o medo e a austeridade mataram há já muito a esperança O medo!

O medo de ser... O medo que tem tudo, O medo tem ambulâncias,

O medo tem sirenes,

O medo tem capacetes e cintos

de segurança

O medo tem terrorismo

Aqui o medo já há muito matou a esperança

E quem não tem medo do nosso medo? Quem não tem medo do monstro das 3 cabeças?

Quem é que ainda o vê como a melhor das possibilidades no meio de todas as crenças? 
Serão heróis? Os que se arrastam até aqui para ser explorados?

Serão heróis esses homens e mulheres que morrem afogados?

Heróis silenciados...

Num silêncio que grita por um mundo melhor.

Mataram esse utopista!!! Não.

Nem sequer tiveram que disparar sobre ele,

Ele suicidou-se quando tentava viver, e atrás dele seguiram outros

Sem medo, sem medo de já estarem mortos

Sem medo dessa repetição

Porque mesmo que lhes mostrem repetidamente a ideia de morte eles acreditam que não a vão repetir Em movimentos limitados, eles expandem-se nesse acto de amor Será um refugiado emancipado apenas um refugiado morto?

Ou será ele um sintoma dessa utopia urgente e necessária?

E mesmo não sabendo se é possível ou não, será ele o único em condições para responder? Vindo ele dessa exclusão abissal intolerável e diária.

Aqui deste lado (e nestas condições) dizem que a utopia é impossível Enquanto o excesso de capital cresce eternamente e nunca é suficiente Enquanto não existirem limites para o dinheiro e a propriedade Enquanto o medo avassalador estiver sempre presente

Aqui deste lado tentamos mais, sempre mais, para no final irmos para um lugar melhor, o paraíso... Sem saber que a nossa esperança imposta consome outras esperanças

E em pleno juízo seguimos, com a nossa meta na felicidade de ter mais, Com o nosso sonho implementado de fora, do nada duma coisa que não é natural nem humana, mas que nos é plantada Já não há flores utópicas a crescer neste jardim...

Porque para alguns é necessário plantar a ruptura,

Mas para a maioria não

Porque para uns criar os seus próprios valores é já uma revolução Porque para uns não se submeter ao que é imposto é a única forma de emancipação

E quem vai perceber essa sabedoria dos periféricos?

Quem vai chegar até esse ponto de humildade?

Quando a elite está condicionada pela sua própria superioridade

Quem vai ter peito para encarar a dificuldade de uma pessoa sem universidade?

Quem vai querer largar as teorias para abraçar as utopias?

As utopias das vivências e da sabedoria Quem vai largar as teorias que geram facilmente arrogância?

Para abraçar a humildade intrínseca onde há sabedoria e esperança?

Quem vai pensar para além da sua condição?

Expandir o Presente, encolher o Futuro e aumentar as possibilidades de alternativas?

Quando há poucas alternativas...

Quem vai se lembrar do mais importante na vida - dos afectos?

E de que não existe um ser melhor do que outro

Mas sim atitudes melhores do que outras Será que ser utópico é uma dessas atitudes?

Quando mesmo a utopia dos pobres pode gerar a repitação dos ricos 
Porque é preciso manter a maioria na ignorância

Para continuarem a construir as nossas estradas

Para continuarem a costurar as nossas roupas

Para conrinuarem a plantar o que comemos

Para continuarem a fazer a base $d a$ sociedade sem terem a consciência de que são a parte mais importante! Para se continuarem a sentir fracos, invisíveis, impotentes...

E se a utopia é procurar uma humanidade melhor Quando ainda não existe humanidade? E se a utopia procura um território melhor

Quando já não existe esse território?

Já não interessa transpôr essa linha abissal

Convém ficar em cima, no topo, dessa linha O caos é o espaço ideal para ocorrer a transição emancipatória

Mas do outro lado as leis que nos regulamentam não são suficientes Há todo um espaço de leis ausentes onde os mais excluídos continuam a lutar pacificamente

Porque paz significa mente

E a utopia contemporânea está nas mentes como dissidência, como insurgência

Como um caminhante que desconhece o seu caminho mas sabe qual é a sua realidade

É a presença de querer ser futuro no desconhecido

E cada passo é pesado mas não existe a hipótese de não avançar

$\mathrm{Na}$ mala tem novos planos e infinitas possibilidades

Mas no bolso, mais à mão, tem a vontade de as conquistar
E vai lutar por elas, vai escavar onde nunca foi escavado

Vai escavar o silêncio, e fazer as questões que ficaram por perguntar

A sua identidade é múltipla, inacabada, sempre em processo de reconstrução Uma identidade em curso sujeita a constante reivenção

Para ele não existe fracasso porque desconhece os seus direitos, ou as leis que o regulamentam

Por isso resiste, persiste, sem coerência e eficácia garantida

E quanto mais à vontade me sente na fronteira, melhor se explora e emancipa Viver na fronteira em suspenção, num espaço vazio, num tempo entre tempos

O seu carácter (e o seu coração) é aberto, inacabado, autónomo e criativo, e vem das margens, da periferia, da fronteira, da linha abissal

O seu passo é excêntrico, exagerado, subversivo, turbulento e transitório A sua meta é inventar tudo, incluindo o próprio acto de inventar É um ser híbrido, provisório e temporário, e as suas raízes se deslocam tão naturalmente como o solo que as sustenta

Porque mais difícil do que crescer asas que voam,

É crescer asas com raízes

E nesse local ela cria raízes e laços preciosos porque são raros, precários e vitalmente úteis

Ali, nessa micro-fronteira utópica, são todas clandestinas, ilegais, indocumentadas, deslocadas, refugiadas em busca de asilo Com um pé na terra e outro sem Estado, prosseguem pacíficas, esse é o seu estado 
Pensam ir para Norte mas vão para Sul, vão desnorteadas

Já não há meios para atingir os fins porque desconhecem esse Monstro que as assombra

Já podem disparar sobre a utopista, Disparem contra a utopista!
Disparem contra a utopista até que ela caia no chão

Disparem com as vossas balas inúteis, quando ela morre por auto-determinação Porque para ela "cada momento é eterno enquanto dura”.

\section{Renan Inquérito}

Rapper, poeta e geógrafo

Doutorando no Programa de Pós-Graduação em Geografia

Instituto de Geociências e Ciências Exatas, Universidade Estadual Paulista (Campus Rio Claro) Av. 24-A, nº1515, Bela Vista, Rio Claro-SP, CEP: 13506-900, Brasil

Contacto: renaninquerito@gmail.com

\section{Raquel Lima}

Doutoranda do Programa Pós-Colonialismos e Cidadania Global no Centro de Estudos Sociais da Universidade de Coimbra

Colégio de São Jerónimo, Largo Dom Dinis, Apartado 3087, 3000-995 Coimbra, Portugal

Contacto: raquellima@ces.uc.pt 